\title{
License Plate Auction of Bidder with Different Risk Appetite
}

\author{
Yi-Tian WU \\ East China University of Science and Technology \\ ECUST \\ Shanghai, China \\ E-mail: tkong941009@163.com
}

\author{
Jia-Hua SUN \\ East China University of Science and Technology \\ ECUST \\ Shanghai, China \\ E-mail: jimmysjh@163.com
}

$$
\begin{gathered}
P_{x}(\text { win })=P\left(G>\left\{g_{i}\right\}_{1}\right)+P\left(\left\{g_{i}\right\}_{1}>G\right. \\
\left.>\left\{g_{i}\right\}_{2}\right)+\cdots+P\left(\left\{g_{i}\right\}_{k-1}>G>\left\{g_{i}\right\}_{k}\right) \\
=C_{n-1}^{0} F[h(G)]^{n-1}+C_{n-1}^{1} F[h(G)]^{n-2}[1-F(h(G))] \\
+\cdots+C_{n-1}^{k-1} F[h(G)]^{n-k}[1-F(h(G))]^{k-1} \\
=\sum_{i=1}^{k} C_{n-1}^{i-1}[1-F(h(G))]^{i-1} F[h(G)]^{n-i}
\end{gathered}
$$

\section{THE DISCRIMINATE AUCTION MODEL}

Model hypothesis:(1)The number of the same License plate is $\mathrm{k}$ (2)The number of the bidders is $\mathrm{n}(n \geq k)$ (3)Each auctioneer can only get a license plate (4)The auction is a non-cooperative game (5)The valuation of bidders obey the same distribution function and won't change according to other information.

Every bidder have the valuation $v_{i}$ of the auction, the valuation of bidders is independent and obey the same distribution function $F\left(v_{i}\right) . F\left(v_{i}\right)$ Is strictly increasing and differentiable in the Domain $[0, \theta]$.And the probability density function if $f\left(v_{i}\right)$. Every bidder will submit the price $g_{i}$ according to the valuation $v_{i} \cdot g_{i}=g\left(v_{i}\right)$ Is monotonically increasing and differentiable. According to the auction $g_{i} \leq v_{i}$.

Let's investigate the bidder $\mathrm{X}$. His valuation is $v_{x}$.His bid function is $G=g_{x}=g\left(v_{x}\right)$. Other bidders' valuation and bid function is $v_{i}, g_{i}=g\left(v_{i}\right)(\mathrm{i}=1,2 \ldots \mathrm{n}$ and $i \neq x)$. $P_{X}$ (win) Represents the probability that the bidder $\mathrm{X}$ win. We definite the income function of the bidder $\mathrm{X}$

$$
R_{x}=\left(v_{x}-G\right) \times P_{x}(\text { win })
$$

We introduce the inverse function $h\left(g_{i}\right), h\left(g_{i}\right)=v_{i}$. The function $\mathrm{h}$ is monotonous, so
So,

$$
\begin{aligned}
R_{x}= & \left(v_{x}-G\right) \times \\
& \sum_{i=1}^{k} C_{n-1}^{i-1}[1-F(h(G))]^{i-1} F[h(G)]^{n-i}
\end{aligned}
$$

To solve the problem conveniently. We introduce the $L_{i}(x)=[1-F(x)]^{i-1} F(x)^{n-i}$, so

$$
R_{x}=\left(v_{x}-G\right) \times \sum_{i=1}^{k} C_{n-1}^{i-1} L_{i}[h(G)]
$$

For the bidder $\mathrm{X}$, His best bid $\mathrm{G}$ is the bid that can make the biggest $R_{x}$. So

$$
\begin{aligned}
\frac{\partial R_{x}}{\partial G}= & \left(v_{x}-G\right) \times \sum_{i=1}^{k} C_{n-1}^{i-1} L_{i}^{\prime}[h(G)] \cdot h^{\prime}(G) \\
& -\sum_{i=1}^{k} C_{n-1}^{i-1} L_{i}[h(G)] \\
= & 0
\end{aligned}
$$

For the bidder X: $G=g_{x}=g\left(v_{x}\right), h(G)=v_{x}$, $h^{\prime}(G)=1 / g^{\prime}\left(v_{x}\right)$,then integral

$$
G=v_{x}-\frac{\sum_{i=1}^{k} C_{n-1}^{i-1} \int_{0}^{v_{x}} L_{i}(y) d y}{\sum_{i=1}^{k} C_{n-1}^{i-1} L_{i}\left(v_{x}\right)}
$$


Let put $L_{i}(x)=[1-F(x)]^{i-1} F(x)^{n-i}$ into the expression. We get the best bid strategy.

\section{BIDDER'S BEST STRATEGY WITH DIFFERENT RISK APPETITE}

In reality, everybody's risk appetite is different. For the bidders has different risk appetite, their bids are reason reasonably different. We classify the bidders has different risk appetite for three categories. The three categories are risk bidders, neutral bidders and conservative bidders. Their corresponding bidding function is $g_{1}, g_{2}, g_{3}$. The number of three kinds of bidders are $n_{1}, n_{2}, n_{3}$ $\left(n_{1}+n_{2}+n_{3}=n\right)$. The number of three kinds of bidders winning are $k_{1}, k_{2}, k_{3}$, The remaining assumptions are the same as the above model.

Considering the bidder $\mathrm{X}$,His valuation and bid is $v_{x}$ and G. We definite the income function $R_{x}=\left(v_{x}-G\right) \times P_{x}($ win $)$. Bidder $\mathrm{X}$ is the bidders of three categories. We definite the three bids $G_{1}, G_{2} G_{3}$ according to three categories. So the income function is

$$
\begin{aligned}
R_{x}= & \left(v_{x}-G_{1}\right) \cdot P_{x}^{\text {risky }}(\text { win }) \\
& +\left(v_{x}-G_{2}\right) \cdot P_{x}^{\text {neutral }}(\text { win }) \\
& +\left(v_{x}-G_{3}\right) \cdot P_{x}^{\text {conservative }}(\text { win })
\end{aligned}
$$

We introduce the symbol $\left\{g_{i}\right\}_{k}$. The symbol $\left\{g_{i}\right\}_{k}$ represents the kth bid after arranging descending bid $g_{i}$.As shown on the right, $\left\{g_{i}\right\}_{k}$ intersects function $g_{1}, g_{2}$, $g_{3}$, and the abscissa of intersection point are $v_{1}, v_{2}, v_{3}$. (It mean the lowest valuation of the three kinds of bidders if they win).You can see this suitation in the Figure 1.

Considering the risk bidders: the number of the bidders are $n_{1} \cdot v_{1}$ Is the lowest valuation if they win $F\left(v_{1}\right)$ represent the probability that valuation is less than $v_{1}$. So the number of the risk bid winning is $k_{1}=\left[1-\mathrm{F}\left(v_{1}\right)\right] \cdot n_{1}$.

$$
\begin{aligned}
P_{x}^{\text {risky }}(\text { win })= & \sum_{i=1}^{k_{1}} C_{n_{1}-1}^{i-1}\left[1-F\left(v_{x}\right)\right]^{i-1} F\left[v_{x}\right]^{n_{1}-i}, \\
& \text { and } k_{1}=\left[1-F\left(v_{1}\right)\right] \cdot n_{1}
\end{aligned}
$$

As the same inference, we can get the winning probability of the neutral bidders and conservative bidders. So

$$
\begin{gathered}
R_{x}=\left[v_{x}-g_{1}\left(v_{x}\right)\right] \sum_{i=1}^{k_{1}} C_{n_{1}-1}^{i-1}\left[1-F\left(v_{x}\right)\right]^{i-1} F\left[v_{x}\right]^{n_{1}-i} \cdot \frac{n_{1}}{n}+ \\
{\left[v_{x}-g_{2}\left(v_{x}\right)\right] \sum_{i=1}^{k_{2}} C_{n_{2}-1}^{i-1}\left[1-F\left(v_{x}\right)\right]^{i-1} F\left[v_{x}\right]^{n_{2}-i} \cdot \frac{n_{2}}{n}+} \\
{\left[v_{x}-g_{3}\left(v_{x}\right)\right] \sum_{i=1}^{k_{3}} C_{n_{3}-1}^{i-1}\left[1-F\left(v_{x}\right)\right]^{i-1} F\left[v_{x}\right]^{n_{3}-i} \cdot \frac{n_{3}}{n}} \\
k_{1}=\left[1-\mathrm{F}\left(v_{1}\right)\right] \cdot n_{1} \quad k_{2}=\left[1-\mathrm{F}\left(v_{2}\right)\right] \cdot n_{2} \\
k_{3}=\left[1-\mathrm{F}\left(v_{3}\right)\right] \cdot n_{3}
\end{gathered}
$$

Because the bidding strategy is different according to the different risk appetite, we want to find the best valuation. The best valuation $v_{x}$ is what make the $R_{x}$ biggest.

\section{REFERENCES}

[1] Hong Jiang. Game Analysis of Shanghai Private Car License Auction [J]. Financial Economy: Theory, 2013, 23(12):170-172.

[2] Fangxue Li. An Analysis of Shanghai Private Car License Auction [D]. Shanghai:Fudan University, 2011.

[3] Xiaolei Zhao. Amendments to the Shanghai private car license auction recommendations [J]. Scientific development, 2013, 12(9):98-101.

[4] AnshiXie, Yijun Li. The Research Content, Method and Prospect of Auction Theory [J]. Journal of Management, 2004, $1(1): 46-52$.

[5] Vickrey, W. Counter speculation, Auctions, and Competitive Sealed Tenders [J]. Journal of Finance, 1961, 23(16):8-37.

[6] Huaizhi Huang, Ming he,Huanchenhuang. Multi - item optimal auction mechanism [J]. Journal of Shanghai Jiaotong University, 1998, 12(8): 49-51.

[7] Li Liana Brief Analysis of Several aspects of the development of the auction industry [J]. Journal of Beijing Technology and Business University (Social Science Edition), 1998, 12(3): 6163. 


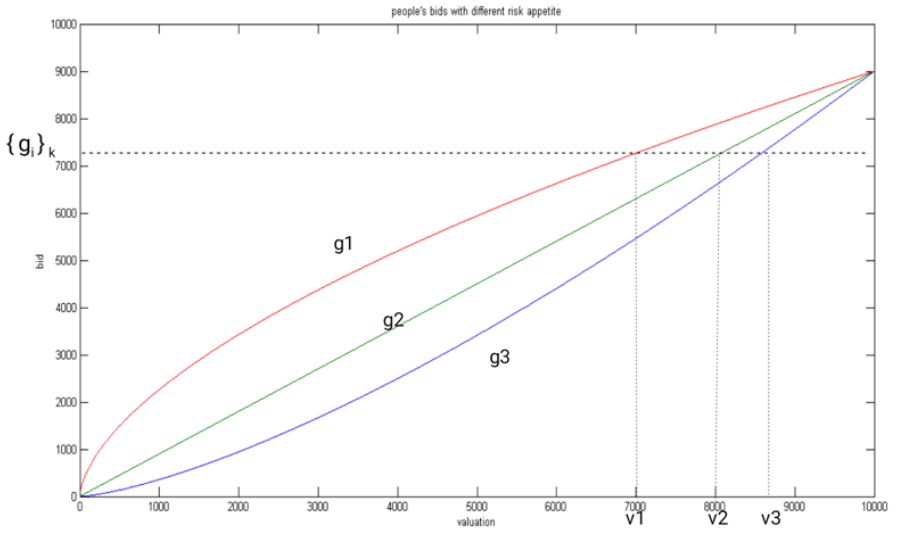

Figure 1. People's bids with different risk appetite 